\title{
Diversity \& Inclusivity in New York State 4-H
}

\author{
Nick Hamilton-Honey ${ }^{1}$
}

This article examines the development of diversity and inclusivity programming within New York State 4-H (NYS 4-H). The beginnings of the diversity and inclusivity initiative within the Cornell Cooperative Extension and NYS 4-H are discussed, along with training techniques for employees and volunteers, outreach to 4$\mathrm{H}$ youth members and club leaders, and the creation of various diversity and inclusivity resources that will be deployed throughout NYS 4-H. [Article copies available for a fee from The Transformative Studies Institute. E-mail address: journal@transformativestudies.org Website: http://www.transformativestudies.org (C2017 by The Transformative Studies Institute. All rights reserved.]

KEYWORDS: 4-H, Diversity, Inclusivity, New York State, Youth Organizations, Positive Youth Development, Safe Space, Cornell Cooperative Extension.

4-H is the largest youth development organization in the world. Today, 4-H can be found in countries located on every continent but Antarctica. 4-H youth clubs in the United States were established in 1902 in Clark County, Ohio. The Smith-Lever Act in 1914 created the Cooperative Extension System within the United States Department of Agriculture and nationalized 4-H ("4-H History"). Within New York State, the Cooperative Extension and 4-H are coordinated by Cornell University Cooperative Extension, generally known as CCE. New York State 4-H (NYS 4-H) is in the process of developing new Diversity and Inclusivity programming and outreach that will hopefully be utilized by other states and potentially even utilized by our national organization. With this Diversity and Inclusivity initiative, NYS 4-H is leading the country in creating greater awareness of and respect for difference, and the strength

\footnotetext{
${ }^{1}$ Nick Hamilton-Honey is a 4-H Educator at Cornell Cooperative Extension of St. Lawrence County. Hamilton-Honey received a M. S. in Resource, Policy and Behavior from University of Michigan and a B. S. in Wildlife and Fisheries Science from Penn State University.
} 